\title{
Análise da rede de colaboração científica sobre biogás
}

Cláudio Marcelo Matos Guimarães

\author{
Mestre em Bioenergia pela Faculdade de \\ Tecnologia e Ciências (FTC). Professor Mestre da \\ Faculdade SENAI CIMATEC
}

Viviane Galvão

Doutora em Biotecnologia pela Universidade
Estadual de Feira de Santana (UEFS) Professora
Doutora do Programa de Pós-Graduação em
Bioenergia da Faculdade de Tecnologia e Ciências
(FTC)

http://dx.doi.org/10.1590/1981-5344/2305

O biogás é um importante tipo de biocombustível obtido a partir de fontes de energia renováveis. Ele pode ser produzido a partir de resíduos urbanos ou industriais e também por decomposição de resíduos orgânicos ou animais. Por esta razão, a quantidade de pesquisas e publicações sobre biogás teve um rápido crescimento nas últimas décadas. Além disso, o número de artigos escritos em coautoria aumentou significativamente. Desta forma, este trabalho construiu a rede de colaboração científica sobre o biogás em um período de 65 anos, ou seja, 1945-2010. Os documentos foram recuperados a partir da base de dados do Web of Knowledge do Institute for Scientific Information (ISI). As consultas foram feitas buscando-se o nome biogás no título do artigo. Assim, três redes foram construídas: autores, instituições e países. No período estudado, foram analisados 1238 trabalhos. Estes documentos foram publicados por 2852 autores diferentes em 1000 instituições distintas pertencentes a 89 países. Os cinco principais países foram a Índia, Alemanha, Estados Unidos da América, China e Dinamarca, respectivamente. Uma observação interessante é que cerca de $85 \%$ das publicações tinham pelo menos um tipo de coautoria entre autores, instituições ou países.

Palavras-Chave: Análise de Rede Social; Coautoria; Biogás. 


\section{Scientific collaboration network analysis on biogas}

Biogas is an important type of biofuel obtained from renewable energy sources. It can be produced from urban or industrial waste and also by decomposition of organic or animal residues. For this reason, the quantity of researches and publications about biogas had a rapid growth in the last decades. Additionally, the number of articles written in co-authorship has increased significantly. In this way, this work built the scientific collaboration network about biogas in a period of 65 years, i.e., 1945-2010. Papers were recovered from the Web of Knowledge database of the Institute for Scientific Information (ISI). Queries were made looking for the biogas name in the paper title. Thus, three networks were constructed: authors, institutions and countries. In the period studied, 1238 papers were analyzed. These documents were published by 2852 different authors in 1000 distinct institutions belonging to 89 countries. The top five countries were India, Germany, The United States of America, China, and Denmark, respectively. An interesting observation is that around $85 \%$ of the publications had at least one type of co-authorship between authors, institutions or countries.

Keywords: Social Network Analysis; Co-authorship; Biogas.

Recebido em 17.12.2014 Aceito em 07.04.2015

\section{Introdução}

Atualmente, a matriz energética mundial é composta, principalmente, por fontes não renováveis de energia como, por exemplo, petróleo, carvão e gás natural. Contudo, uma nova visão de preservação ambiental, impulsionada pelo aquecimento global e pelo alto preço do petróleo, tem contribuído para o aumento de pesquisas buscando novas formas de energia (SILVA et al., 2011). Fontes alternativas de energia são responsáveis por apenas em torno de $15 \%$ da energia consumida no mundo (GUIMARÃES; GALVÃO, 2013; PACHECO, 2006). Um tipo de fonte renovável que se destaca é a biomassa. A biomassa ao ser decomposta pela ação de bactérias pode gerar o biogás. Essa decomposição acontece dentro de biodigestores (PERLINGEIRO, 2014). 
O biogás é composto principalmente de metano $\left(\mathrm{CH}_{4}\right)$ e dióxido de carbono $\left(\mathrm{CO}_{2}\right)$. A depender da eficiência no processo de produção do biogás é possível encontrar entre $50 \%$ e $70 \%$ de metano, $25 \%$ a $45 \%$ de dióxido de carbono e até $5 \%$ de outros gases (nitrogênio, oxigênio, gás sulfídrico, monóxido de carbono, amoníaco) (COELHO et al., 2006; PERLINGEIRO, 2014). O poder calorífico do biogás pode variar entre 22.500 a $25.000 \mathrm{~kJ} / \mathrm{m}^{3}$ (SALOMON; LORA, 2005). No processo da produção do biogás ocorre a degradação de materiais orgânicos de vários tipos, tais como, resíduos orgânicos como lixo doméstico, substratos de atividades agrícolas, dejetos das atividades pecuárias, lodo de esgoto, entre outros. A produção deste biocombustível ocorre em um processo anaeróbico sem a presença de oxigênio (PECORA et al., 2008).

Os principais microrganismos envolvidos no processo de decomposição da matéria orgânica podem ser agrupados em quatro grupos: bactérias hidrolíticas e fermentativas; bactérias acetogênicas; arqueias metagenômicas e bactérias homoacetogênicas (PERLINGEIRO, 2014). O biogás pode ser utilizado como gás de cozinha, para gerar energia elétrica ou como combustível para veículos. Os resíduos gerados após a decomposição dos materiais orgânicos podem ser utilizados como fertilizantes na agricultura (HOLM-NIELSEN; AL SEADI; OLESKOWICZPOPIEL, 2009). O biogás pode colaborar com a produção de energia de um país e, assim, contribuir para uma maior segurança energética (YANG, ZHANG, LI, 2012).

As últimas décadas foram marcadas por uma elevação na quantidade de publicações científicas sobre biogás. No início do século XX os trabalhos científicos ainda eram predominantemente produções de um único autor. Contudo, atualmente, a maioria das publicações é desenvolvida em colaboração. Este aumento pode ser identificado tanto na fração de trabalhos que apresentam colaboração quanto na quantidade de colaboradores presentes nos artigos (LABAND; TOLLISON, 2000). A mudança nesse cenário acarretou para o ambiente acadêmico uma nova visão sobre as produções científicas, pois a colaboração propicia um ganho intelectual quando os envolvidos compartilham ideais (BALANCIERE et al., 2005; MAIA; CAREGNATO, 2008).

As redes de colaboração analisam as relações existentes entre indivíduos, instituições e países. Elas são formadas por pesquisadores que compartilham interesses comuns (MOED, GLÄNZEL, SCHMOCH, 2005). Este tipo de rede pode ser estudado a partir da Análise de Rede Social (ARS). O interesse da comunidade acadêmica sobre ARS vem crescendo nas últimas duas décadas devido ao desenvolvimento da informática. A ARS pode ser estudada a partir do conjunto de atores e das relações existentes entre eles (WASSERMAN, 1994). A definição dos atores depende do problema pesquisado. No caso da colaboração científica, o ator pode ser um país, uma instituição ou um pesquisador. As ligações entre os atores são obtidas através das relações de coautoria (GLANZEL, 2002).

Há diversos trabalhos acadêmicos sobre rede de colaboração científica em diferentes áreas do conhecimento. Assim, este tipo de 
investigação possui um caráter interdisciplinar e alguns exemplos podem ser encontrados nos seguintes trabalhos: colaboração científica sobre biogás em trabalhos desenvolvidos no Brasil (GUIMARÃES; GALVÃO, 2014), estudo quantitativo das produções acadêmicas brasileiras sobre biodiesel (ANDRADE; GALVÃO, 2014), análise das publicações de autores brasileiros em doenças negligenciadas (MOREL et al., 2009) e tuberculose (VASCONCELLOS; MOREL, 2012), estudo bibliométrico de periódicos de Administração, Ciências Contábeis e Turismo editados no Brasil (ARAÚJO et al., 2014), relações de coautoria nos artigos da revista Química Nova (SOUZA et al., 2012) e Biomass and Bioenergy (DE SOUZA E GALVÃO, 2014), impactos dos nomes nas propriedades de redes sociais (BARBASTEFANO, 2013), análise de redes de colaboração científica sob as novas tecnologias de informação e comunicação: um estudo na Plataforma Lattes (BALANCIERI et al., 2005), o peso da colaboração internacional e o papel das redes sociais (PACKER; MENEGHINI, 2006), colaboração e produção científica em ciência da informação (BRANDÃo PARREIRAS; SILVA, 2007; DA SILVA; BARBOSA; DUARTE, 2012; PARREIRAS et al., 2006), análise bibliométrica de publicações sobre recursos hídricos (WANG et al., 2011), geoestatística (ZHOU et al., 2007) e astrofísica (HEIDLER, 2011).

Dado o contexto apresentado fica evidenciado que o processo de cooperação entre os pesquisadores é um assunto com importância na atualidade, pois áreas distintas têm realizado estudos para compreender como a parceria acadêmica está ocorrendo. Desta forma, esse trabalho tem como objetivo construir, caracterizar e analisar a rede de colaboração científica sobre biogás, a partir de relações de coautoria dos artigos publicados sobre este tema. O período selecionado foi compreendido entre 1945 e 2010. Neste estudo foi feito um levantamento de todos os artigos indexados na base de dados do ISI/Web of Science.

\section{Metodologia}

Os dados da rede de colaboração científica sobre o biogás foram levantados através do banco de dados Web of Science do ISI Web of Knowledge, acessado pelo Portal da CAPES. A base de dados selecionada foi a coleção principal do Web of Science. A pesquisa foi realizada buscando-se o termo 'Biogas' no título do artigo científico. O período selecionado para análise foi compreendido entre 1945 e 2010. Todos os dados levantados foram registrados em planilhas e obtidos entre junho e julho de 2014. Essa consulta levantou 1238 artigos, sendo o primeiro publicado em 1966 e o último teve sua publicação em dezembro de 2010. Os dados registrados de cada artigo foram: quantidade de autores, quantidade de países, quantidade de instituições, nome de cada país e nome de cada instituição.

Neste trabalho, três redes foram construídas: países, instituições e autores. Os dados desses artigos foram mapeados para se 
obter os atores (países, instituições e autores) de cada rede. As relações entre os vértices são obtidas através da coautoria, ou seja, se dois atores colaboram em um mesmo artigo, então os vértices serão conectados por uma aresta na rede dos atores. Para determinar as colaborações os dados foram tratados da seguinte forma: em uma publicação com três países $(A$, $B$ e $C)$, as relações teriam a seguinte distribuição ( $A B, A C, B C)$. Esse levantamento foi feito também para as instituições em todos os 1238 artigos.

Uma padronização dos nomes das instituições também foi realizada para não ocorrer duplicidade e, assim, evitar a geração de vértices múltiplos representando a mesma instituição. A rede de autores foi gerada com o auxílio do programa Network Workbench Tool (2006). Esse programa utiliza os dados dos autores obtidos diretamente do ISI Web of Knowledge. A rede de países e a rede de instituições foram geradas a partir de uma planilha de dados. Assim, com base nos dados coletados os programas Pajek (BATAGEL]; MRVAR, 2004) e Gephi (BASTIAN, HEYMANN, JACOMY, 2009) foram utilizados para a visualização e análise da rede de autores, países e instituições.

\section{Resultados e discussão}

No período de 1945 a 2010, pode-se observar a evolução da quantidade de artigos, países, instituições e autores publicando sobre biogás. Este trabalho analisou 1238 artigos científicos publicados por 2852 autores e 1000 instituições distintas pertencentes a 89 países. O Gráfico 1 apresenta a quantidade de artigos por período selecionado. Para um melhor tratamento dos dados, os resultados foram distribuídos em intervalos de tempo começando com o período compreendido até 1980 . Os períodos selecionados mostram um aumento no número de publicações. Esta ampliação foi mais significativa no último intervalo e este fato mostra uma forte ascensão nas pesquisas sobre biogás.

Gráfico 1 - Publicações sobre biogás por período

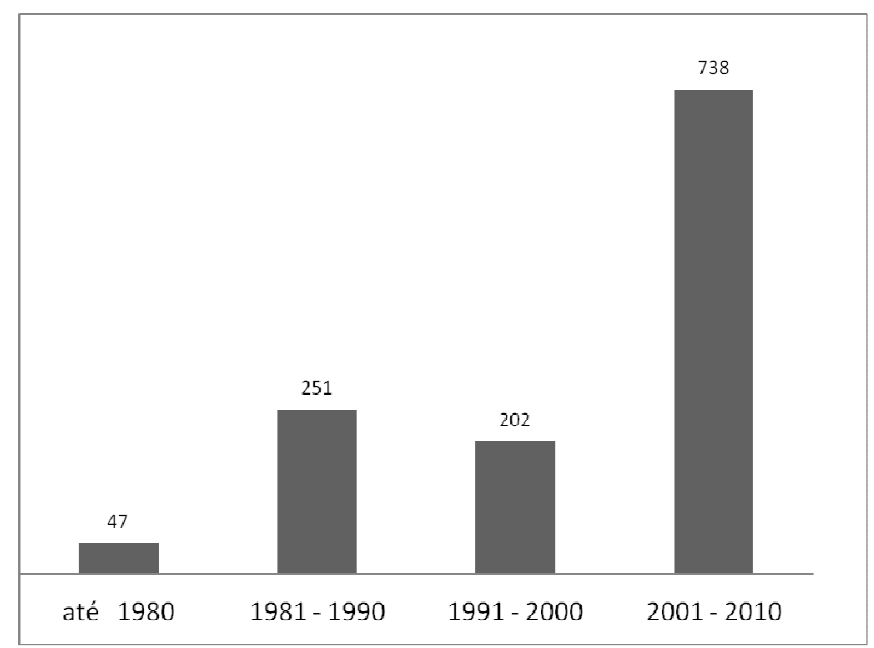

Fonte: Dados da pesquisa. 
O Gráfico 2 apresenta as revistas científicas com maior quantidade de publicações sobre biogás. O periódico mais representativo é a Bioresource Technology. Essa publicação é editada pela Elsevier e o seu fator de impacto foi de 5,039 em 2013. A editora Elsevier é responsável por editar 4 dessas 5 revistas científicas. A exceção é Water Science and Technology publicada pela Iwa Publishing com fator de impacto 1,212 em 2013.

Gráfico 2 - Revistas científicas que mais publicaram sobre biogás no período de 1945 a 2010

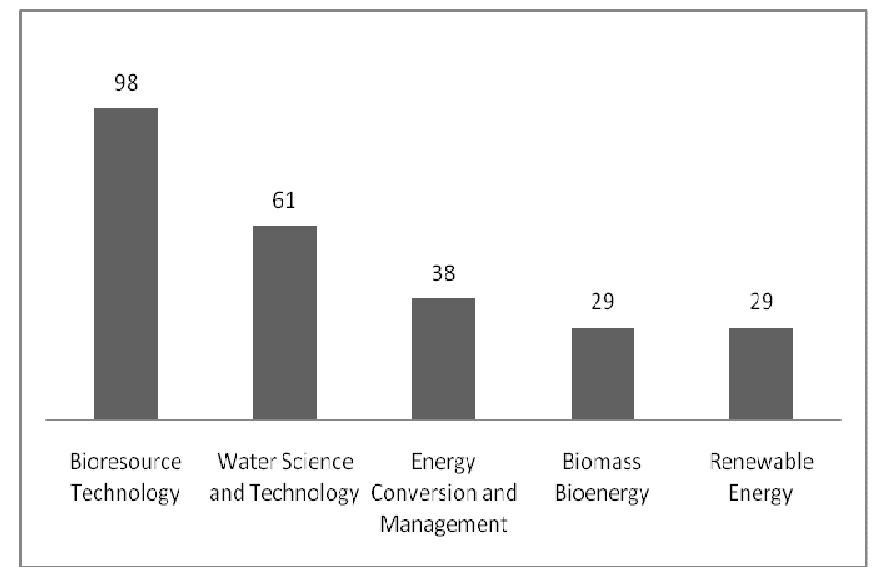

Fonte: Dados da pesquisa.

\subsection{Redes de países}

A análise dos dados apresentou 89 países distintos que publicaram sobre biogás no período de 1945 a 2010. O Gráfico 3 apresenta o quantitativo acumulado de países. De acordo com a figura 1 , no período compreendido de 1945 até 1980 houve 47 publicações distribuídas entre quinze países. Neste intervalo, três países se destacaram, foram eles: Índia, Inglaterra e Alemanha. O segundo período, compreendido de 1945 até 1990, apresenta 49 países. Como o resultado é acumulativo, isso significa que os 15 países do primeiro intervalo fazem parte do total de 49 países. Portanto, do primeiro intervalo para o segundo ocorreu um aumento de 34 novos países com publicações sobre biogás. Do segundo intervalo para o terceiro, o aumento também foi de 17 novos países. No último período ocorreu um acréscimo de 23 novos países em relação ao penúltimo intervalo, totalizando assim 89 países.

Gráfico 3 - Quantitativo acumulado de países 


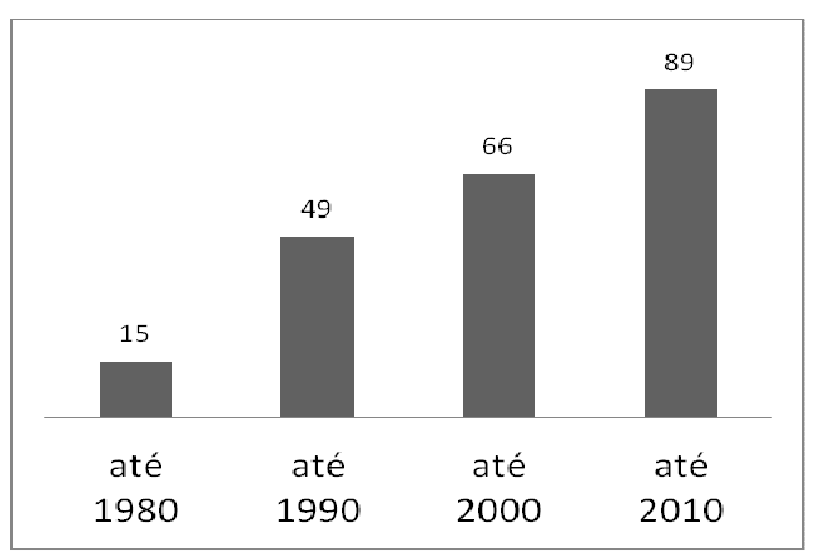

Fonte: Dados da pesquisa.

O Gráfico 4 apresenta os quatro países com maior número de publicações sobre biogás. A Índia se destaca nesse cenário, pois publicou aproximadamente $89 \%$ a mais do que o segundo país, a Alemanha. Entre os quatro primeiros, dois são da Ásia, um da Europa e um da América do Norte. Em relação a quantidade de artigos, o continente asiático supera os outros dois em de $50 \%$ nas publicações. A produção de artigos sobre biogás no Brasil só aparece na décima quarta posição com 28 publicações. Em 2007, a Alemanha ultrapassou os Estados Unidos da América na produção de biogás e se tornou o país com a maior produção deste biocombustível (REN21, 2009). Contudo, a Alemanha não lidera em produção científica sobre este tema no período pesquisado.

Gráfico 4 - Os quatro países com maior número de publicações sobre biogás

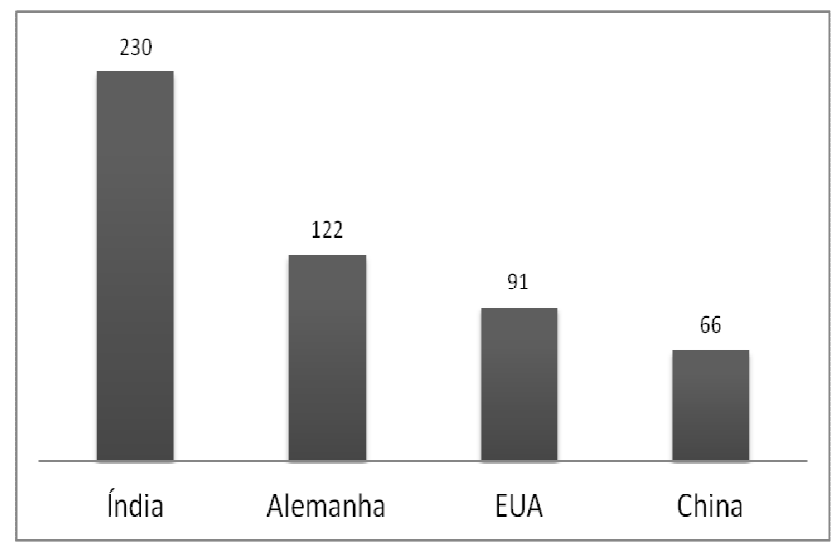

Fonte: Dados da pesquisa.

Na Tabela 1 estão distribuídos os números de países por artigo publicado. Neste trabalho 1238 artigos científicos foram analisados. Contudo, 52 deles não continham no campo endereço o país em que o artigo foi desenvolvido, por esse motivo a tabela tem um total de 1186 artigos. Esta tabela demonstra que $91 \%$ dos artigos só teve a participação de apenas um país, não existindo colaboração internacional. Para o tema estudado, a colaboração em nível de países ainda é reduzida, pois apenas aproximadamente $9 \%$ dos trabalhos foram desenvolvidos por autores pertencentes a dois ou três países diferentes. 
Tabela 1 - Distribuição do número de países por artigo

\begin{tabular}{ccc}
\hline $\begin{array}{c}\text { Países por } \\
\text { artigo }\end{array}$ & Artigos & $\%$ \\
\hline \hline 1 & 1079 & 91,0 \\
2 & 100 & 8,4 \\
3 & 7 & 0,6 \\
Total & 1186 & 100 \\
\hline
\end{tabular}

Fonte: Dados da pesquisa.

A Figura 1 apresenta a rede de países. Nessa rede pode-se observar 33 comunidades distribuídas da seguinte forma: uma comunidade principal composta por 53 países, uma comunidade com três países (Índia, Nepal e Irlanda do Norte), duas com dois países (Cuba e Tchecoslováquia, Jordânia e Catar) e 29 com apenas um país, ou seja, sem a ocorrência de colaboração. Os países com maiores colaborações dentro dessa rede são: Alemanha, Inglaterra, Estados Unidos e Dinamarca com 14,13, 11 e 9 ligações, respectivamente. Os três países com maior quantidade de colaborações, Alemanha, Inglaterra e USA, estão diretamente interligados. Quando os países sem colaboração ou com duas e três ligações são excluídos, fica-se com apenas uma comunidade onde todos os vértices (países) têm no mínimo uma ligação.

Figura 1 - Rede de países

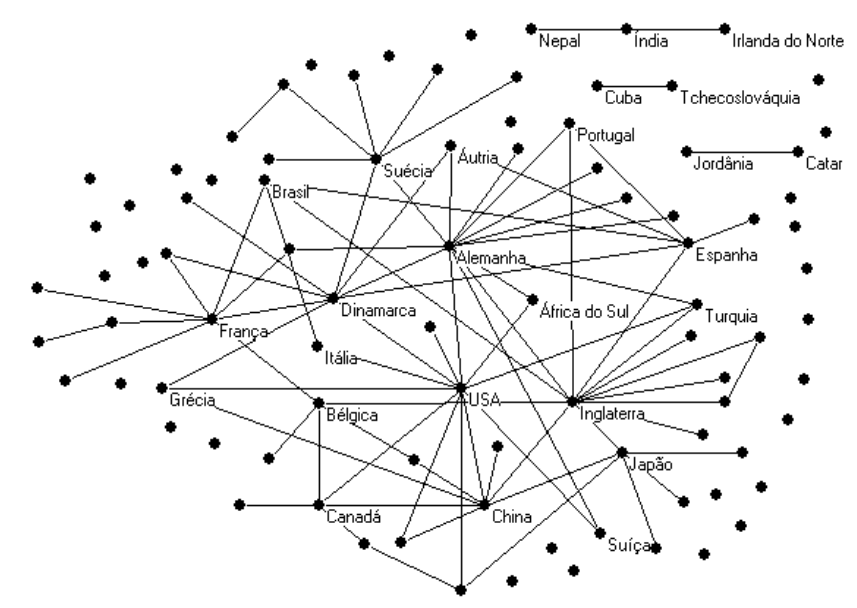

Fonte: Dados da pesquisa.

\subsection{Redes de instituições}

O Gráfico 5 apresenta o quantitativo acumulado de instituições. No período compreendido de 1945 até 1980 houve 47 publicações distribuídas em 35 instituições diferentes. O acumulado do período de 1945 até 2000 foi de 354 instituições um crescimento de 319 novas instituições em relação ao primeiro período. No último período acumulado (até 2010) a quantidade de instituições apresentou por volta de $182 \%$ de aumento em relação ao intervalo anterior. De acordo com essa figura, 
1000 instituições distintas participaram das publicações sobre o biogás no mundo.

Gráfico 5 - Quantitativo acumulado de instituições

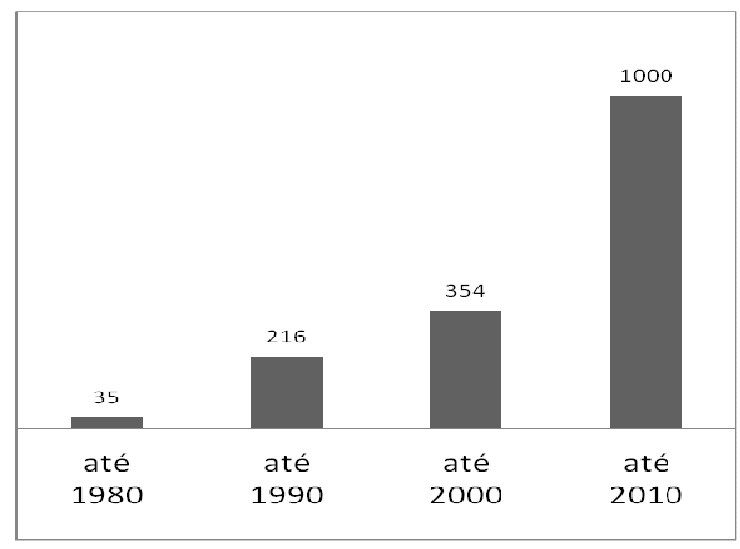

Fonte: Dados da pesquisa.

A Tabela 2 apresenta a distribuição do número de instituições por artigo publicado. Com base nos dados levantados, as 1000 instituições participaram de 1187 publicações. Esse número é diferente do total de 1238 artigos analisados, porque 51 deles não apresentavam no campo endereço o nome da instituição. A maioria dos artigos pesquisados foi desenvolvida sem colaboração institucional, pois cerca de $71 \%$ deles possuíam somente uma única instituição. Um artigo merece destaque, pois teve a coautoria de 7 instituições, apresentando a participação de 17 autores e 3 países (Inglaterra, Taiwan e Finlândia).

Tabela 2 - Distribuição do número de instituições por artigo

\begin{tabular}{ccc}
\hline Instituições por artigo & Artigos & $\%$ \\
\hline 1 & 843 & 71,1 \\
2 & 239 & 20,1 \\
3 & 78 & 6,6 \\
4 & 21 & 1,8 \\
5 & 4 & 0,3 \\
7 & 1 & 0,1 \\
Total & 1186 & 100 \\
\hline
\end{tabular}

Fonte: Dados da pesquisa.

As cinco instituições que mais publicaram sobre biogás no período pesquisado foram a Indian Institute Technology, Technical University of Denmark, Swedish University Agricultural Science, Indian Agricultural Research Institute e Indian Institute Science, respectivamente. Dessas instituições, 3 pertencem a Índia, 1 a Dinamarca e 1 a Suécia. A Tabela 3 apresenta algumas características da rede de instituições. Nessa rede observam-se 595 comunidades distintas. A maior comunidade possui 67 instituições distintas. Essa rede apresenta 428 instituições sem colaboração, ou seja, foram artigos publicados somente com colaboração 
intrainstitucional. Adicionalmente, ela possui 94 comunidades formadas por 2 instituições.

Tabela 3 - Distribuição do número de instituições por artigo

Fonte: Dados da pesquisa.

\begin{tabular}{lc}
\hline Quantidade de Instituições & 1000 \\
Comunidades & 595 \\
Quantidade de instituições na maior comunidade & 67 \\
Instituições sem colaboração & 428 \\
Comunidades formadas por 2 instituições & 94 \\
\hline
\end{tabular}

\subsection{Rede de autores}

o gráfico 6 apresenta o quantitativo acumulado de autores que publicaram sobre biogás no período pesquisado. Os resultados encontrados apresentaram em sua totalidade 2852 autores. A entrada de novos autores na rede foi mais acentuada no último período analisado com mais de $200 \%$ de novos autores. Esse fato indica que a comunidade acadêmica está cada vez mais interessada em desenvolver novas pesquisas nessa temática e, consequentemente, publicar esses dados em revistas científicas.

Gráfico 6 - Quantitativo acumulado de autores

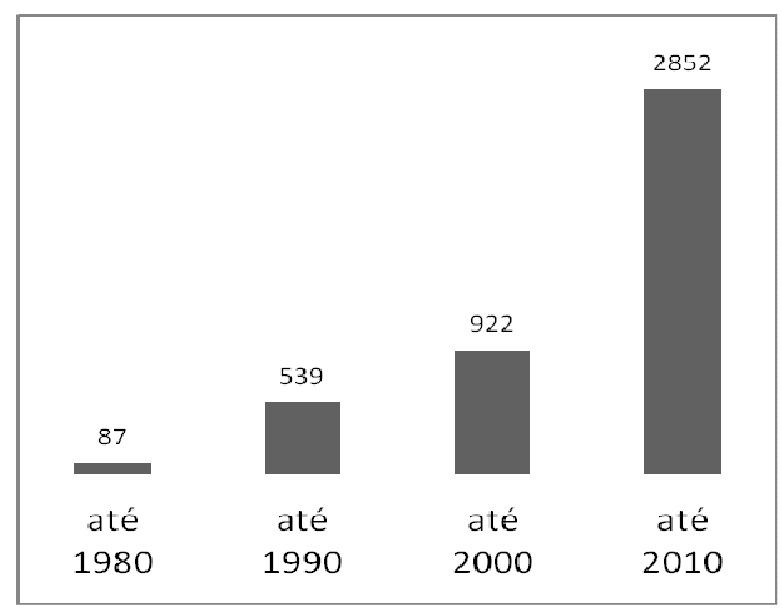

Fonte: Dados da pesquisa.

A tabela 4 apresenta a quantidade de autores por artigo. Em torno de $85 \%$ dos artigos apresentaram coautoria e cerca de $34 \%$ dos trabalhos envolveram a participação entre 4 e 20 autores. Contudo, a maioria dos trabalhos foram publicados por 2 ou 3 autores em colaboração. Os destaques desses dados levantados estão relacionados a três artigos com a colaboração de 13, 17 e 20 autores. O artigo com 13 autores envolve também três países e cinco instituições e o com 17 autores envolve três 
países e sete instituições. O artigo que apresenta 20 autores colaborando possui apenas duas instituições e dois países.

Tabela 4 - Distribuição do número de autores por artigo

\begin{tabular}{ccc}
\hline $\begin{array}{c}\text { Autores por } \\
\text { artigo }\end{array}$ & Artigos & $\%$ \\
\hline 1 & 191 & 15,4 \\
2 & 304 & 24,6 \\
3 & 318 & 25,7 \\
4 & 202 & 16,3 \\
5 & 119 & 9,6 \\
6 & 53 & 4,3 \\
7 & 23 & 1,9 \\
8 & 12 & 1,0 \\
9 & 2 & 0,2 \\
11 & 2 & 0,2 \\
13 & 1 & 0,1 \\
17 & 1 & 0,1 \\
20 & 1 & 0,1 \\
Total & 1238 & 100 \\
\hline
\end{tabular}

Fonte: Dados da pesquisa.

A Tabela 5 apresenta algumas características da rede de autores. Essa rede possui 2851 autores participando de 715 comunidades distintas. Desse total de autores, 132 não colaboraram com nenhum outro autor da rede, ou seja, publicaram um artigo científico individualmente. A maior comunidade possui 74 autores. Esse fato indica que os grupos de pesquisas estão interagindo pouco entre si na temática estudada e, com isso, há uma quantidade reduzida de membros nas comunidades.

Tabela 5 - Resultados da rede de autores

\begin{tabular}{lc}
\hline Quantidade de Autores & 2851 \\
Comunidades & 715 \\
Quantidade de autores na maior comunidade & 74 \\
Autores sem colaboração & 132 \\
\hline
\end{tabular}

Fonte: Dados da pesquisa.

\section{Considerações finais}

Este trabalho analisou 1238 artigos científicos que continham o termo biogás no título. O período selecionado nesta pesquisa abrangeu de 1945 a 2010. Esses artigos foram publicados por 2852 autores e 1000 instituições distintas pertencentes a 89 países. Entretanto, o primeiro artigo científico, indexado no banco de dados do Web of Science do ISI Web of Knowledge, com a palavra biogás presente título foi publicado somente em 1966. De 1966 a 2010, tem-se um período total de 45 anos e 
este intervalo corresponde a uma média de aproximadamente 28 artigos por ano.

A Índia foi o país que mais publicou sobre biogás, pois cerca de $18,5 \%$ de toda publicação sobre este tema foi produzido por esta nação. Adicionalmente, a Alemanha participou com $10 \%$ e os Estados Unidos da América com 7,5\%. Estes três países pertencem a três continentes distintos: Ásia, Europa e América. Contudo, todos os continentes participaram dessas publicações mapeadas. Um ponto a destacar sobre a Índia está relacionado a quantidade de colaborações, pois esse país só colaborou com outros dois países (Irlanda do Norte e Nepal). A Alemanha e os Estados Unidos da América apresentaram 14 e 11 colaborações com outros países, respectivamente.

Entre as cinco instituições que mais publicaram artigos sobre biogás têm-se que três são da Índia e as outras duas pertencem à Dinamarca e à Suécia. A análise das instituições apresentou também que 844 artigos foram publicados sem colaboração interinstitucional. Um dado interessante é que a grande maioria das publicações (aproximadamente $85 \%$ ) apresentou pelo menos um tipo de coautoria entre autores, instituições ou países.

\section{Agradecimentos}

Este trabalho teve suporte da CAPES (Coordenação de Aperfeiçoamento de Pessoal de Nível Superior).

\section{Referências}

ANDRADE, I. L.; GALVÃO, V. Rede de colaboração científica das principais oleaginosas envolvidas na produção do biodiesel no Brasil. Diálogos \& Ciência, v. 34, p. 24-27, 2014.

ARAÚjO, R. M. et al. Periódicos em ação: um estudo exploratóriobibliométrico na área de Administração, Ciências Contábeis e Turismo. Perspectivas em Ciência da Informação, v. 19, n. 1, p. 90-114, 2014.

BALANCIERI, R. et al. A análise de redes de colaboração científica sob as novas tecnologias de informação e comunicação: um estudo na Plataforma Lattes. Ciência da Informação, v. 34, n. 1, 2005.

BARBASTEFANO, R. G. et al. Impactos dos nomes nas propriedades de redes sociais: um estudo em rede de coautoria sobre sustentabilidade. Perspectivas em Ciência da Informação, v. 18, n. 3, p. 78-95, 2013.

BASTIAN, M.; HEYMANN, S.; JACOMY, M. Gephi: an open source software for exploring and manipulating networks. ICWSM, v. 8, p. 361-362, 2009.

BATAGELJ, V.; MRVAR, A. Pajek: analysis and visualization of large networks. In: JÜNGER, M.; MUTZEL, P. (Ed.). Graph Drawing Software. Berlin: Springer Berlin Heidelberg, 2004. p. 77-103.

BRANDÃO, W. C.; PARREIRAS, F. S.; SILVA, A. B. O. Redes em Ciência da Informação: evidências comportamentais dos pesquisadores e tendências 
evolutivas das redes de coautoria. Informação \& Informação, v.12, n. especial, 2007.

COELHO, S. T. et al. A conversão da fonte renovável biogás em energia. In: CONGRESSO BRASILEIRO DE PLANEJAMENTO ENERGÉTICO, 5., Brasília, 2006. Anais... Brasília-DF: [s.n.], 2006.

DA SILVA, A. K. A.; BARBOSA, R. R.; DUARTE, E. N. Rede social de coautoria em ciência da informação: estudo sobre a área temática de "Organização e Representação do Conhecimento". Informação \& Sociedade: Estudos, v.22, n.2, p. 63-79, 2012.

DE SOUZA, L. S.; GALVÃO, V. Rede de colaboração científica na área de bioenergia no Brasil: um estudo baseado nos artigos do periódico Biomass \& Bioenergy. In: EXLER, R. B.; SAMPAIO, L. P.; TEIXEIRA, L. P. B. (Org.). Bioenergia: um diálogo renovável. Salvador: Vento Leste, 2014. v. 3. p. 90-99.

GLANZEL, W. Coauthorship patterns and trends in the sciences (19801998): a bibliometric study with implications for database indexing and search strategies. Library Trends, v. 50, n. 3, p. 461-473, 2002.

GUIMARÃES, C. M. M.; GALVÃO, V. Colaboração científica sobre biogás no Brasil. In: EXLER, R. B.; SAMPAIO, L. P.; TEIXEIRA, L. P. B. (Org.). Bioenergia: um diálogo renovável. Salvador: Vento Leste, 2014. v. 3. p. 128-139.

HEIDLER, R. Cognitive and social structure of the elite collaboration network of astrophysics: a case study on shifting network structures. Minerva, v. 49, n. 4, p. 461-488, 2011.

HOLM-NIELSEN, J. B.; AL SEADI, T.; OLESKOWICZ-POPIEL, P. The future of anaerobic digestion and biogas utilization. Bioresource Technology, $\mathrm{v}$. 100, n. 22, p. 5478-5484, 2009.

LABAND, D.; TOLLISON, R. Intellectual collaboration. Journal of Political Economy, v. 108, n. 3, p. 632-662, 2000.

MAIA, M.; CAREGNATO, S. Co-autoria como indicador de redes de colaboração científica. Perspectivas em ciência da informação, v. 13, n. 2, p. 18-31, 2008.

MOED, H. F.; GLÄNZEL, W.; SCHMOCH, U. Handbook of quantitative science and technology research. [s.I.]: Springer Netherlands, 2005.

MOREL, C. M. et al. Coauthorship network analysis: a powerful tool for strategic planning of research, development and capacity building programs on neglected diseases. PLOS Neglected Tropical Diseases, v. 3, n. 8, p. 501, 2009.

NETWORK Workbench Tool. Versão 1.0.0. Michigan: Indiana University, Northeastern University; University of Michigan, 2006. Disponível em: <http://nwb.cns.iu.edu/>. Acesso em: 15 jun. 2014. 
PACHECO, F. Energias renováveis: breves conceitos. Conjuntura e Planejamento, n. 149, p. 4-11, 2006.

PACKER, A. L.; MENEGHINI, R. Articles with authors affiliated to Brazilian institutions published from 1994 to 2003 with 100 or more citations: I-the weight of international collaboration and the role of the networks. Anais da Academia Brasileira de Ciências, v. 78, n. 4, p. 841-853, 2006.

PARREIRAS, F. S. et al. REDECI: colaboração e produção científica em ciência da informação no Brasil. Perspectivas em ciência da informação, v. 11 , n. 3, p. 302-317, 2006.

PECORA, V. et al. Biogás e o mercado de créditos de carbono. Anais do Rio Oil \& Gas Expo and Conference. Rio de Janeiro, 2008.

PERLINGEIRO, C. A. G. Biocombustíveis no Brasil: fundamentos, aplicações e perspectivas. Rio de Janeiro: Synergia, 2014.

REN21. Update, renewable energy policy network for the 21st Century. Paris: REN21 Secretariat, 2009. Renewables Global Status Report: 2009.

SALOMON, K. R.; LORA, E. E. S. Estimativa do potencial de geração de energia elétrica para diferentes fontes de biogás no Brasil. Biomassa \& Energia, v. 2, n. 1, p. 57-67, 2005.

SILVA, A. S. et al. A importância da utilização das energias renováveis para a construção de um desenvolvimento econômico sustentável para o Brasil e para a Bahia. Diálogos e Ciência, n. 27, p. 1-14, 2011.

SOUZA, C. G. et al. Redes de colaboração científica na área de química no Brasil: um estudo baseado nas coautorias dos artigos da revista Química Nova. Química Nova, v. 35, n. 4, p. 671-676, 2012.

VASCONCELLOS, A. G.; MOREL, C. M. Enabling policy planning and innovation management through patent information and co-authorship network analyses: a study of tuberculosis in Brazil. PLOS ONE, v. 7, n. 10, p. e45569, 2012.

WANG, M.-H. et al. Research articles published in water resources journals: A bibliometric analysis. Desalination and Water Treatment, v. 28, n. 1-3, p. 353-365, 2011.

WASSERMAN, S. Social network analysis: methods and applications. Cambridge University Press, 1994.

YANG, Y.; ZHANG, P.; LI, G. Regional differentiation of biogas industrial development in China. Renewable and Sustainable Energy Reviews, n. 16, p. 6686-6693, 2012.

ZHOU, F. et al. Scientometric analysis of geostatistics using multivariate methods. Scientometrics, v. 73, n. 3, p. 265-279, 2007. 